\title{
Reinventing clinical investigation
}

Concerned about the "thinning ranks of clinical investigators" who conduct research of immediate relevance to human medicine, Harold Varmus, Director of the US National Institutes of Health (NIH), says he wants to do something to remedy the situation. Varmus, an MD who nonetheless has spent his own career doing basic laboratory science, told a major meeting of clinical researchers in San Diego* that, after a year and a half at the helm of NIH, he wants now to learn "more about what you do."

To that end, Varmus, who is studiously appointing blue ribbon committees to evaluate various aspects of NIH's activities, announced the creation of a special NIH panel on clinical research, which will report directly to him. The panel will be headed by haematologist David G. Nathan of Harvard Medical School whose forthcoming book, Genes, Blood, and Courage was cited by Varmus as a description of clinical research at its intellectual best.

The Nathan panel's mandate, which overlaps ongoing or recently completed studies by other Varmus-appointed groups, includes the following:
- Clinical research. What is it? (It is amazing but true that there is more than one definition.)

- Clinical research centres. There are dozens in the United States. Are there too many? Does their work overlap? Are they as efficiently staffed and run as possible? - Attracting and financing clinical investigators. These days, the big prizes and kudos in science go to people doing basic research, leaving clinical investigators feeling like second-class citizens. A better system of rewards and recognition needs to be in place, Varmus believes.

- Financing. Because these studies include patients, who often are hospitalized for a period, they tend to be quite expensive. A proposal to charge patients' insurance companies for care that is not explicitly related to the research study is highly controversial in light of a tradition in the United States that provided ancillary care free of charge to patients who volunteered to be the subjects of certain clinical studies.

- Scandal. Varmus and NIH were caught off-guard by revelations that one physician participating in an international, multihospital breast cancer study did not follow the study's protocol. The panel has been asked to review policies regarding clinical studies and responses to real or alleged misconduct.

- Indemnity. In a litigious society, clinical investigators are threatened by law suits if something goes wrong, even in the absence of negligence or error. Would a system that compensated research patients who suffer untoward side-effects advance the cause of medical science?

The list goes on. The long and short of it is that the panel is being asked to review clinical investigation in each of its many aspects with a view to producing a comprehensive strategic plan for the future. The group will meet for the first time in early July.

\section{BARBARA J. Culliton}

* Varmus spoke at the annual Clinical Research Meeting, sponsored by the American Federation for Clinical Research, the American Society for Clinical Investigation, and the Association of American Physicians.

\section{A prescription for clinical research?}

Although all of the facts are not yet in, the Division of Research Grants (DRG) last month revealed tentative plans for studies that might reassure those concerned that clinical research does not fare as well as basic research during peer review. This perception is widespread (see right) among clinical researchers.

The results of a report released last December appeared to confirm this view. In particular, the report showed that in study sections that receive only a few clinical applications, a smaller percentage of the clinical research than might be expected made it into the ranks of those recommended for funding.

However, the report begs many questions. One of the most obvious being: Was the definition of clinical research apt? The definition was "Research conducted with human subjects (or on material of human origin such as tissues, specimens and cognitive phenomenon) for which the investigator directly interacts with human subjects."

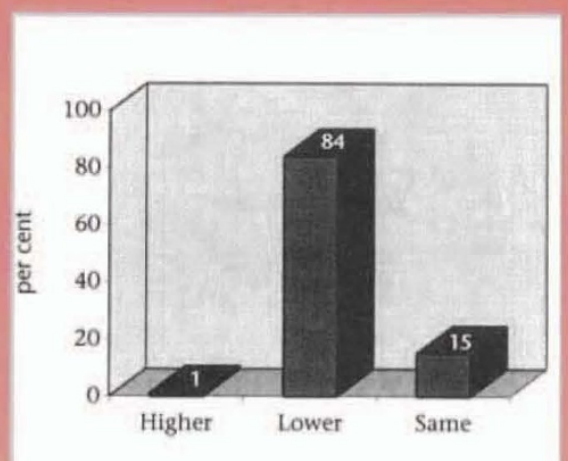

Question: "Clinical investigators at my institution have a higher, lower or the same chance as basic investigators in getting an R01 funded."
It excluded research looking at the therapeutic value of a treatment and work with animal models. Some argue for the inclusion of one or both of these in any assessment of how big a piece of the funding pie goes to clinical research. A group being set up by Varmus (see above) should resolve this and other questions.

In the meantime, Thomas Braciale of the University of Virginia and chair of the DRG's advisory committee recommends that the DRG goes ahead with suggested pilot studies that might throw more light on the subject. The first would probably be in the fields of endocrinology and reproductive biology. These fields were chosen because the study sections that review work in these areas are among those that receive low percentages of clinical research.

Helen GavaghaN 